\title{
Decreased oxygen permeability of EVOH through molecular interactions
}

\author{
Zs. Péter ${ }^{1,2}$, Cs. Kenyó ${ }^{1,2}$, K. Renner ${ }^{1,2^{*}}$, Ch. Kröhnke ${ }^{3}$, B. Pukánszky $y^{1,2}$ \\ ${ }^{1}$ Laboratory of Plastics and Rubber Technology, Department of Physical Chemistry and Material Science, Budapest \\ University of Technology and Economics, P.O. Box 91, H-1521 Budapest, Hungary \\ ${ }^{2}$ Institute of Materials and Environmental Chemistry, Research Centre for Natural Sciences, Hungarian Academy of \\ Sciences, P.O. Box 286, H-1519 Budapest, Hungary \\ ${ }^{3}$ Clariant Produkte (Deutschland) GmbH, D-81477 Munich, Germany
}

Received 16 March 2014; accepted in revised form 29 May 2014

\begin{abstract}
Poly(ethylene-co-vinyl alcohol) of 48 mol\% ethylene content was modified with N,N'-bis(2,2,6,6-tetramethyl-4piperidyl)-isophthalamide (Nylostab SEED) to decrease the oxygen permeability of the polymer. The additive was added in a wide concentration range from 0 to $10 \mathrm{wt} \%$. The structure and properties of the polymer were characterized with various methods including differential scanning calorimetry, X-ray diffraction, mechanical testing, optical measurements and oxygen permeation. Interactions were estimated by molecular modeling and infrared spectroscopy. The results showed that oxygen permeation decreased considerably when the additive was added at less than $2.0 \mathrm{wt} \%$ concentration. The decrease resulted from the interaction of the hydroxyl groups of the polymer and the amide groups of the additive. The dissolution of the additive in the polymer led to decreased crystallinity, but also to decreased mobility of amorphous molecules. Stiffness and strength, but also deformability increased as a result. Above $2 \mathrm{wt} \%$ the additive forms a separate phase leading to the deterioration of properties. The success of the approach represents a novel way to control oxygen permeation in EVOH and in other polymers with similar functional groups capable of strong interactions.
\end{abstract}

Keywords: material testing, oxygen permeability, crystalline structure, solubility, hydrogen bonds

\section{Introduction}

The number of functional and smart packaging materials increases continuously and they are used already in everyday practice in increasing quantities [1-4]. The main functions targeted for various products are small oxygen permeability or oxygen scavenging [5-7], humidity control [8-12], regulated ethylene content [13], antimicrobial effect [14-17], adsorption of odorous materials, or the opposite, the release of desirable aromas $[18,19]$. Intensive research and development work is carried out on these materials all over the world, but mostly in industry.
Controlling oxygen permeability is especially important in the pharmaceutical industry and in food packaging. The oxygen permeability of polymers varies in a wide range covering several orders of magnitudes from a few hundred to a few hundredths or even thousands of $\mathrm{cm}^{3} \mathrm{~mm} / \mathrm{m}^{2} / 24 \mathrm{~h} / \mathrm{bar}$ [20]. Ethylene-vinyl alcohol copolymers (EVOH) offer extremely good protection against oxygen [20-25]. The barrier properties of these materials depend on ethylene content [23, 26, 27], crystallinity, temperature [22, 28] and humidity [24, 26-34]. The last factor represents also the major drawback of $\mathrm{EVOH}$, since permeability may increase by orders of magnitudes with increasing water content [28]. Various

\footnotetext{
${ }^{*}$ Corresponding author, e-mail: krenner@mail.bme.hu

(C) BME-PT
} 
solutions exist to overcome this drawback. One of them is the production of multilayer films consisting of an EVOH barrier layer between polyolefin outer layers combined by the use of adhesive functional polymers [27, 35-37]. Development led to the production of packaging films with 9 or 10 layers combining EVOH, polyamide (PA) and polyolefins [38]; microfilms with 30-1000 layers of $0.02-5 \mu \mathrm{m}$ thickness also appeared on the market recently [39].

Another approach to decrease the oxygen permeability and water sensitivity of EVOH is modification by blending [29, 35, 40-49] or by the production of layered silicate nanocomposites [50-57]. $\mathrm{EVOH}$ is combined with polyamides the most frequently, but blending results in decreased crystallinity and the desired improvement in permeability is seldom achieved. Better results are claimed with layered silicates which are supposed to exfoliate completely in $\mathrm{EVOH}$, increase tortuosity and decrease permeability considerably. Unfortunately the control of structure is difficult in polymer/layered silicate nanocomposites [58], complete exfoliation is rarely achieved [59], organophilic silicates are quite expensive and they often discolor the product [60]. All the above presented examples prove the need for solutions, which result in a further decrease in the oxygen permeability of $\mathrm{EVOH}$.

During the literature study of the topic, we have not found any indication of using a small molecular weight additive for the improvement of the barrier properties of poly(ethylene-co-vinyl alcohol) against oxygen. The general idea and goal of our project was to explore this possibility and use N, $\mathrm{N}^{\prime}-$ bis(2,2,6,6-tetramethyl-4-piperidyl)-isophthalamide (Nylostab SEED), which was originally developed for the protection of pigmented polyamides against light induced decomposition. The additive proved to be also an efficient nucleating agent in polyamides. Nucleation of EVOH might increase crystallinity thus decreasing oxygen permeability and water sensitivity as well. The compound contains several functional groups, which may interact with the $-\mathrm{OH}$ group of $\mathrm{EVOH}$ thus changing free volume and offering a further route to modify oxygen permeability. EVOH containing the additive in a relatively wide composition range was produced and various properties were determined in the study. A detailed analysis of structure and interactions is pre- sented in the paper to shed light onto the reason of the observed effects and correlations.

\section{Experimental}

The poly(ethylene-co-vinyl alcohol) polymer $(\mathrm{EVOH})$ used in the experiments was the Eval G156 grade acquired from Eval Europe, Belgium. Its ethylene content is $48 \mathrm{~mol} \%$, density $1.12 \mathrm{~g} / \mathrm{cm}^{3}$ and its melt flow index is $6.4 \mathrm{~g} / 10 \mathrm{~min}$ at $190^{\circ} \mathrm{C}$ and $2.16 \mathrm{~kg}$. The additive, N,N'-bis(2,2,6,6-tetramethyl-4-piperidyl)-isophthalamide (Nylostab SEED, in further discussion Seed) is the product of Clariant, Germany. The chemical structure of the additive is shown in Figure 1. It is a sterically hindered amine (HALS) product, a crystalline material with melting temperature of $272^{\circ} \mathrm{C}$ and density of $1.12 \mathrm{~g} / \mathrm{cm}^{3}$. Experiments were carried out at 0, 0.1, 0.2, 0.3, 0.4, $0.5,0.8,1.0,2.5,5.0,7.5$ and $10.0 \mathrm{wt} \%$ additive contents.

Components were homogenized in a Brabender single screw extruder at $30 \mathrm{rpm}$ and 260-270-280$260^{\circ} \mathrm{C}$ zone temperatures. The extruder was equipped with a die of single orifice of $3 \mathrm{~mm}$ diameter. The extruded strand was cooled in air and then pelletized. The pellets were compression molded to plates of $1 \mathrm{~mm}$ and films of about $100 \mu \mathrm{m}$ thickness at $190^{\circ} \mathrm{C}$ using a Fontijne SRA 100 machine. Before processing all materials were dried at $100^{\circ} \mathrm{C}$ for 4 hours in an oven and then kept in a desiccator until further use.

Melting and crystallization characteristics and the possible nucleation effect of the additive were determined by differential scanning calorimetry (DSC) using a Perkin Elmer DSC 7 apparatus. The measurements were done on 3-5 mg samples cut from the $1 \mathrm{~mm}$ thick plates. Two heating and a cooling run were carried out at $10^{\circ} \mathrm{C} / \mathrm{min}$ heating and cooling rate in the temperature range of $30-300^{\circ} \mathrm{C}$. Crystallinity was calculated from the enthalpy of fusion $(157.8 \mathrm{~J} / \mathrm{g})$ of the EVOH single crystal of $100 \%$ crystallinity [61]. Crystalline structure was also studied

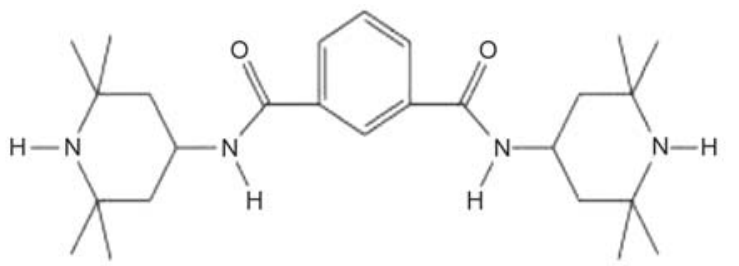

Figure 1. Chemical structure of the additive used in the experiments (Seed) 
by X-ray diffraction. XRD patterns were recorded using a Phillips PW 1830/PW 1050 equipment with $\mathrm{CuK}_{\alpha}$ radiation at $40 \mathrm{kV}$ and $35 \mathrm{~mA}$ in the reflection mode. The traces were recorded in $0.04^{\circ}$ steps with a sampling interval of $1 \mathrm{~s}$ and a rate of $0.04 \% \mathrm{~min}$ in the $2 \theta$ range of $3-43^{\circ}$. Crystallinity was calculated from the XRD traces with the method proposed by Brückner [62].

Molecular interactions were studied by Fourier transform infrared spectroscopy (FTIR). The measurement were carried out in the attenuated total reflection (ATR) mode and the spectra were recorded in the wavelength range of $4000-400 \mathrm{~cm}^{-1}$ with 16 scans in $4 \mathrm{~cm}^{-1}$ steps using a Perkin Elmer Spectrum 100 apparatus. Molecular modeling was used to check possible interactions between the additive and the polymer and to estimate their strength. To reduce the necessary time and computer capacity to a reasonable level, we selected a small molecular weight model compound (1,4-buthanediol) representing the repeating unit of the polymer. We focused only on specific interactions, i.e. hydrogen bonds, and neglected dispersion interactions in the analysis. All the geometry optimizations for the model system were performed at the density functional theory (DFT) level using the MPW1B95 (modified Perdew and Wang exchange and Becke's 1995 correlation) functional [63] as well as the $6-31++\mathrm{G}^{* *}$ basis set [64].

The density of the polymer was measured at room temperature in $\mathrm{n}$-hexane using a pycnometer. A Systec Instruments Model 8000 apparatus (Thame, Oxfordshire, England) was applied for the permeation measurements, which were carried out according to the ASTM D 3985 standard in three parallel measurements. The test area and thickness of the sample were $50 \mathrm{~cm}^{2}$ and about $100 \mu \mathrm{m}$, respectively, for all specimens. Oxygen transmission rate (OTR) was detected at $23^{\circ} \mathrm{C}$ and $50 \%$ relative humidity. Mechanical properties were characterized by tensile testing using an Instron 5566 machine at $115 \mathrm{~mm}$ gauge length and $5 \mathrm{~mm} / \mathrm{min}$ cross-head speed on five parallel specimens with $1 \times 10 \mathrm{~mm}$ dimensions according to the ISO 527 standard. The haze of the samples was determined with the help of a ColorQuest (HunterLab, Reston, US) apparatus.

\section{Results and discussion}

The results are presented in several sections. First, the effect of the additive on the properties of the poly- mer is shown and then the structure of the latter is analyzed in detail. Solubility and interactions are considered in the next two sections, and then correlations are discussed and a brief reference is made to consequences for practice in the last section.

\subsection{Properties}

The main hypothesis of the project was that similarly to PA, Seed will nucleate also EVOH, increase crystallinity and oxygen permeability decreases as an effect. The OTR of films is plotted against additive content in Figure 2.

Permeability decreases at small Seed concentrations as expected, but increases considerably at larger additive contents. The initial decrease seems to be small, but it is approximately $30 \%$, which is more than any effect achieved by blending and only slightly smaller than the claimed decrease resulting from the use of layered silicates $(\sim 50 \%)[55,56]$, but without the disadvantageous effect of the latter. We may conclude as a result that the additive influences oxygen permeability indeed, but the reason for the effect must be identified by further study and analysis. Changes in other properties and the analysis of structure should offer more information about the mechanism and origin of the effect. The increase in permeability at large additive content merits further considerations as well. If nucleation and changes in crystalline structure result in the improvement observed, one would expect a saturation effect, OTR remaining constant at large SEED contents. Obviously, some other, probably structural changes lead to the minimum in the OTR vs. additive content correlation

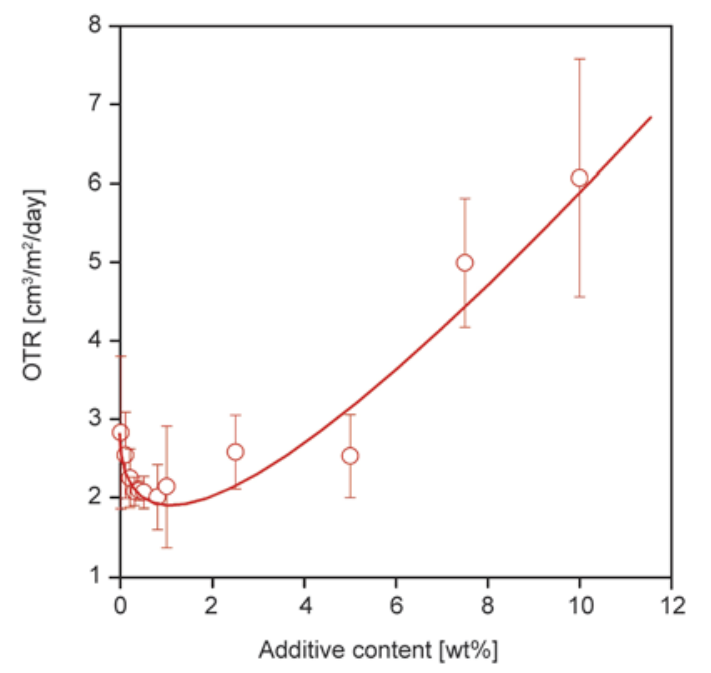

Figure 2. Effect of Seed content on the oxygen permeation of EVOH films 
resulting from the superposition of two different effects.

The influence of the additive on the Young's modulus of the polymer is presented in Figure 3. The results strongly corroborate our preliminary assumption, stiffness increases with increasing additive content presumably because of increasing crystallinity and probably larger lamella thickness [65]. Similarly to OTR, two stages can be observed in the composition dependence of Young's modulus as well. Stiffness increases quite steeply at small and somewhat more moderately at larger additive contents, above 1.5-2.0 wt\%. Ultimate tensile properties are presented as a function of additive content in Figure 4 . The changes in tensile strength agree more or less with the results presented in Figures 2 and 3, i.e. strength increases considerably at small additive

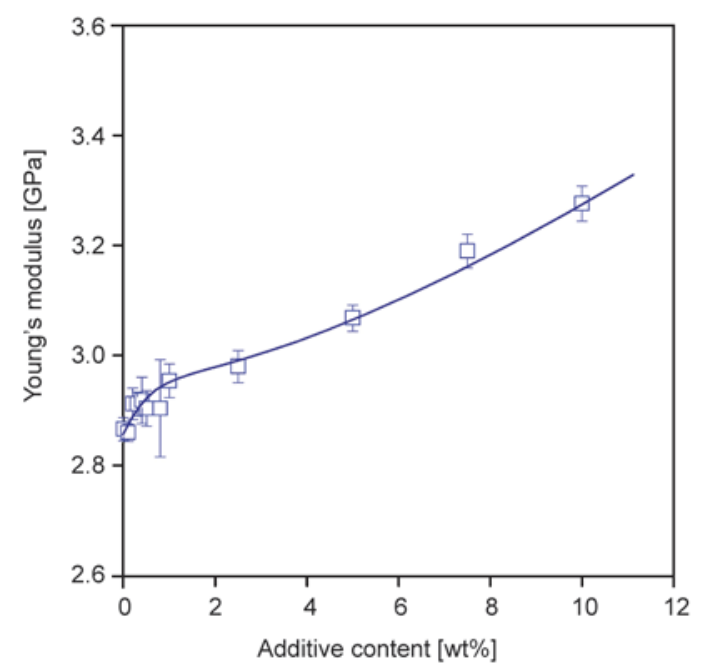

Figure 3. Dependence of the stiffness of EVOH plates on additive content

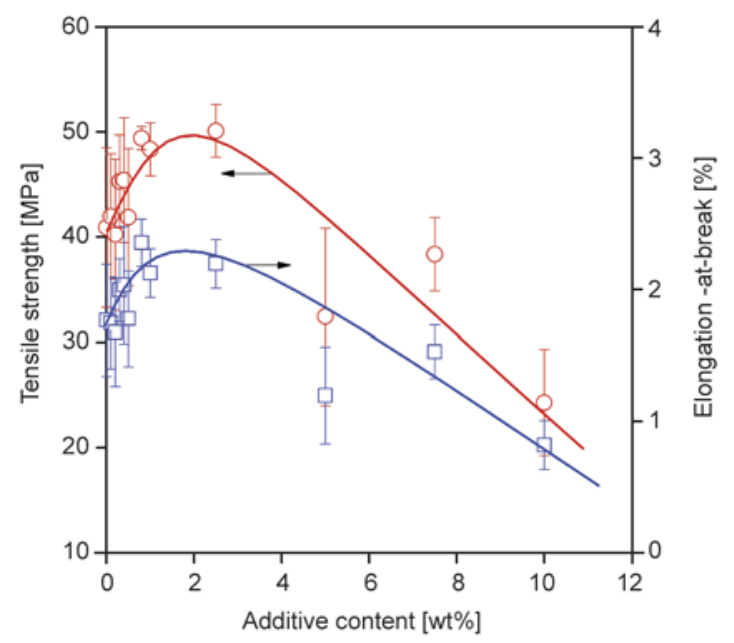

Figure 4. Ultimate tensile properties of EVOH plotted against Seed content. Symbols: (०) tensile strength, ( $\square$ ) elongation-at-break. contents. On the other hand, the composition dependence of deformability seems to contradict our initial assumption. Changing crystallinity leading to larger stiffness usually results in decreased deformability and not to increased elongation-at-break. Simultaneous increase of strength and deformability often indicates changing structure, like physical or chemical cross-linking or decreased crystallinity. Moreover, the maximum in both quantities hints also to further structural changes, to the probability of phase separation caused by the limited solubility of the additive in the polymer. A heterogeneous, twophase structure with weak interfacial interaction of the phases could result in the decrease of strength and deformability at large additive contents.

\subsection{Structure}

The modulus of crystalline polymers is determined mainly by crystallinity and the thickness of the lamella grown during crystallization [65]; lamella thickness increases with increasing crystallization temperature, thus also with nucleation [66, 67]. The heat of fusion proportional to crystallinity is plotted against additive content in Figure 5. Rather surprisingly crystallinity does not increase, but decreases with increasing additive content. The detailed analysis of the DSC traces recorded in the two heating and the cooling runs indicated that Seed does not nucleate EVOH. All quantities related to crystallinity (heat of fusion, heat of crystallization) decreased with increasing additive content, the melting temperature was constant in both heating runs and the temperature of crystallization also decreased as

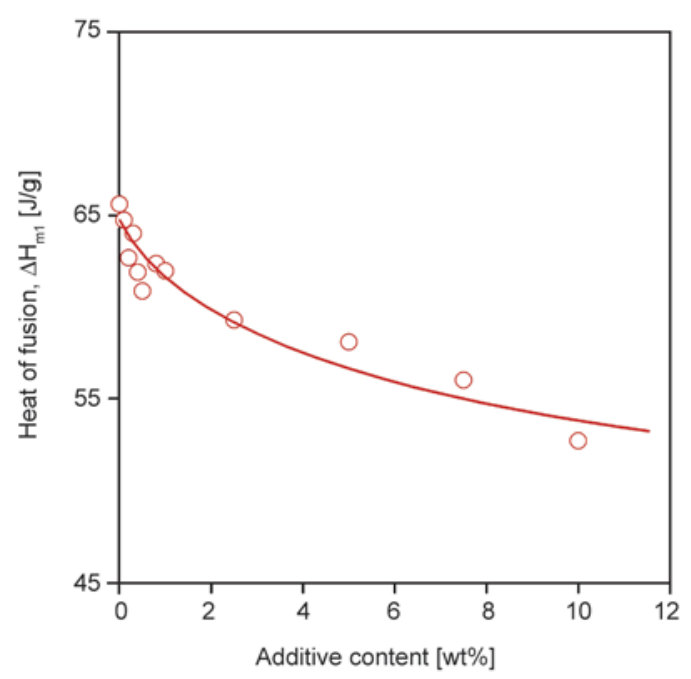

Figure 5. Effect of additive content on the crystallinity $\left(\Delta H_{\mathrm{m} 1}\right)$ of $\mathrm{EVOH}$ 


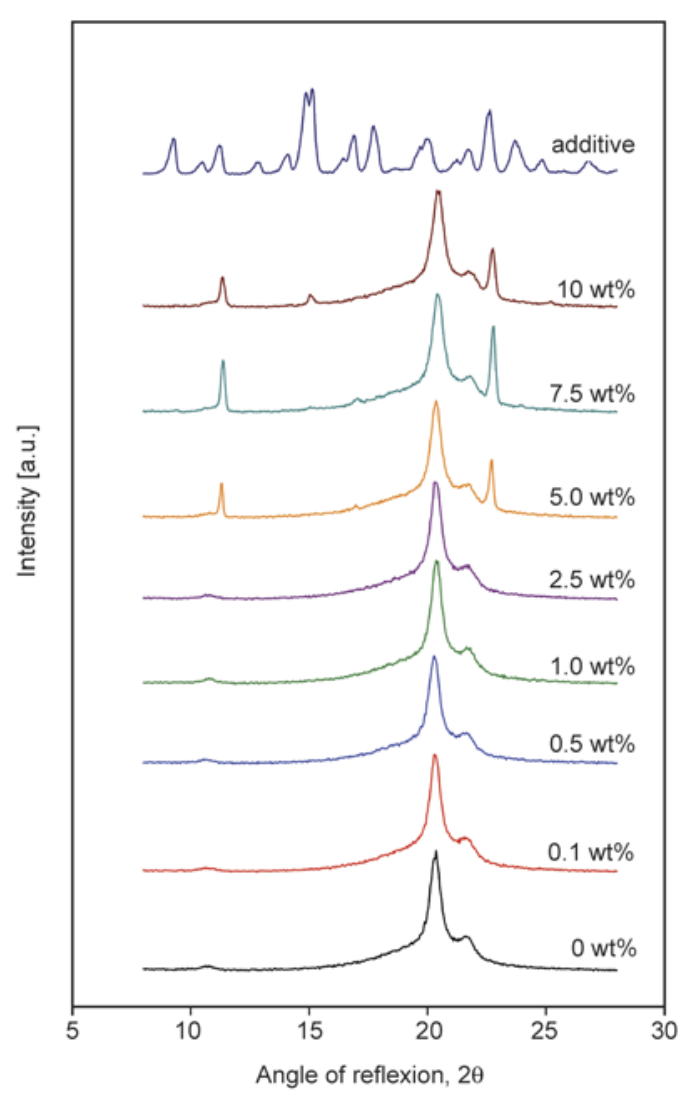

Figure 6. XRD traces of EVOH containing various amounts of Seed additive

Seed content increased. These results clearly indicate that the decrease in OTR as an effect of the additive is not caused by changing crystalline structure, but by some other factor or factors.

XRD spectra were also recorded and analyzed in order to confirm the modification of crystalline structure. The traces are presented in Figure 6 for selected compositions. Crystal form does not change at small additive content, but new peaks appear on the traces above $2.5 \mathrm{wt} \%$ Seed content. Possible changes in crystallinity cannot be deduced from the traces in this form, but their quantitative analysis by the approach of Brückner [62] allowed the determination of crystallinity, which is plotted against additive content in Figure 7. The correlation is practically identical to the one presented in Figure 5, and plotting the two quantities, i.e. the heat of fusion and crystallinity determined by XRD, against each other yielded a straight line with negligible scatter (not shown). These results further confirm that crystallinity does not increase, but decreases as an effect of the additive, this latter does not nucleate EVOH and the changes observed in properties are caused by another factor, probably by interactions.

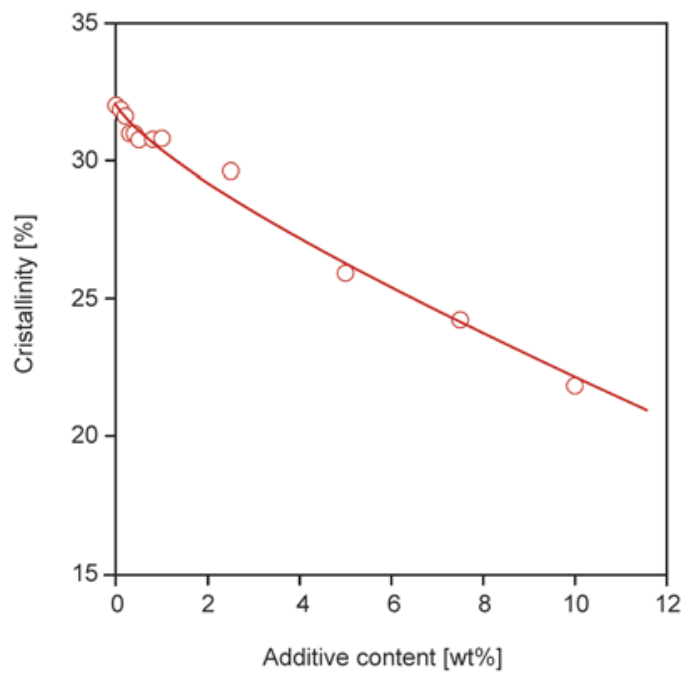

Figure 7. Decreasing crystallinity with increasing additive content as determined by XRD analysis

\subsection{Solubility}

The extremes in Figures 2 and 4 indicated the modification of structure, which cannot result from changing crystallinity, since it decreases monotonously with increasing additive content. A possible reason might be phase separation, the limited solubility of the additive in the polymer. A further indication for the existence of separate phases was supplied by the XRD traces presented in Figure 6. Above $2.5 \mathrm{wt} \%$ Seed content new peaks appear in the traces, which correspond to certain reflections of the additive. Obviously, the additive is present as a separate phase in crystalline form at these concentrations.

Changes in the optical properties of polymers may also reveal phase changes. Crystalline units as well as dispersed particles are often large enough to interfere with visible light and this interference results in considerable haze that is often used for the characterization of the optical properties of plastic products. Haze is the total flux of light scattered within the angular range between 2.5 and $90^{\circ}$ and normalized to the total transmitted flux [68]. Haze indicates changes in optical properties more sensitively than transparency, which is the fraction of incident light that passes through an object. The haze value of the plates containing different amounts of Seed is plotted as a function of composition in Figure 8 . The correlation is very interesting and clearly reveals all structural changes in the polymer as an effect of increasing additive content. Haze decreases at small additive concentrations due to decreasing crystallinity. At around $2 \mathrm{wt} \%$ Seed con- 


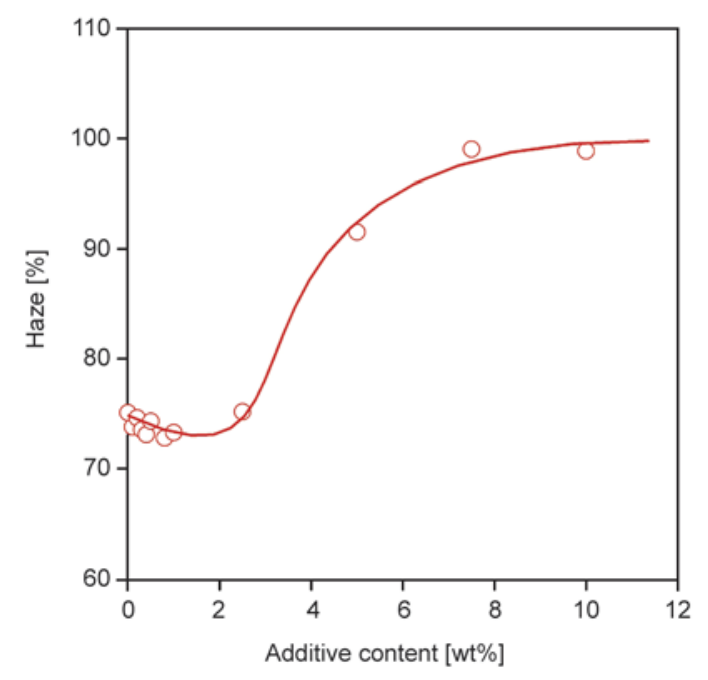

Figure 8. Effect of additive content on the haze of $1 \mathrm{~mm}$ thick EVOH plates

tent haze starts to increase and reaches practically $100 \%$ at the largest additive content because of phase separation and the presence of large dispersed particles. These changes agree well both with the XRD results (Figure 6), but also with the changes in mechanical properties (Figures 3 and 4).

\subsection{Interactions}

The functional groups of the additive and the hydroxyl groups of the polymer may develop relatively strong interactions. Molecular modeling by using the DFT approach showed that hydrogen bonds can form between the two substances indeed (see Figure 9). The two compounds are in the lowest energy state when the hydroxyl group of the polymer and the carbonyl of the additive are at about $2 \AA$ distance from each other which corresponds to the distance of hydrogen bonds. The energy of the interaction is $28 \mathrm{~kJ} / \mathrm{mol}$, which is relatively strong. The interaction should result in a shift of the corre-

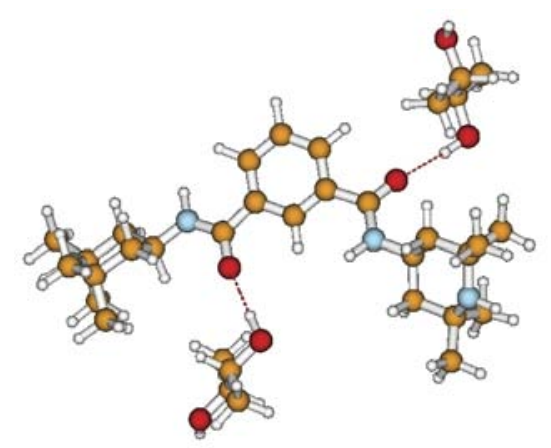

Figure 9. Formation of hydrogen bonds between EVOH and Seed; DFT modeling

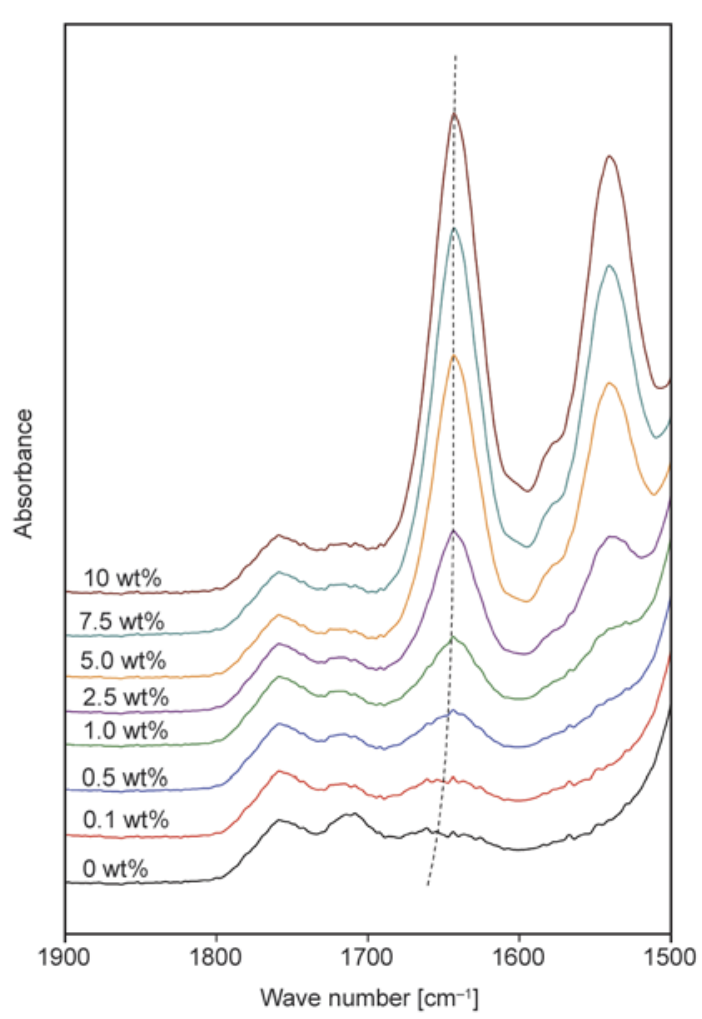

Figure 10. Shift in the position of the carbonyl absorption of amide groups with increasing additive content

sponding absorptions bands in the infrared spectrum of the material.

The spectra are presented in Figure 10 for selected additive contents in the range of the carbonyl vibration of the amide group (around $1650 \mathrm{~cm}^{-1}$ ). A considerable shift can be observed at small additive contents, which seems to level out at larger amounts of Seed, but the spectra in Figure 10 do not allow a more precise determination of band shifts. The results

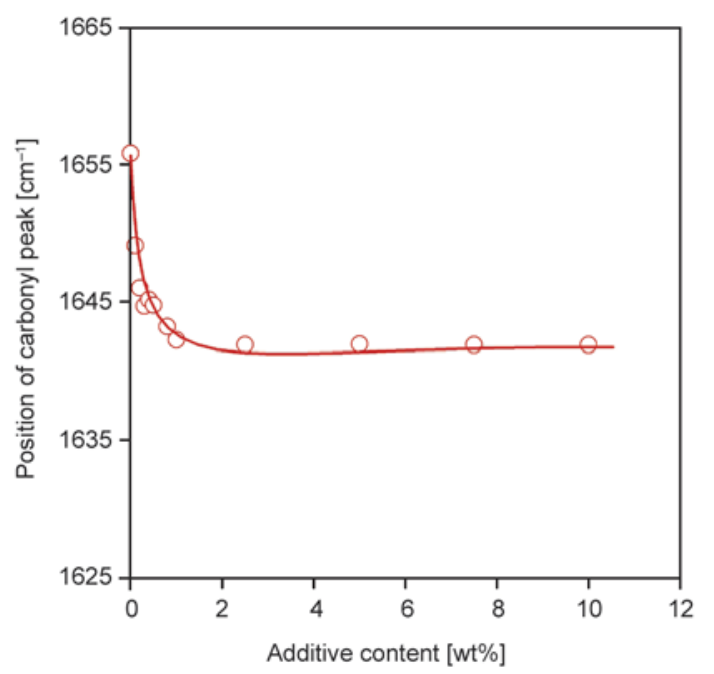

Figure 11. Effect of additive content on the position of the carbonyl absorption of amide groups 
of quantitative analysis are shown in Figure 11, in which the position of the carbonyl absorption is plotted against additive content. The absorption band shifts more than $10 \mathrm{~cm}^{-1}$ wavelength in the range of $0-2 \mathrm{wt} \%$ additive content and remains constant afterwards. The strong shift corroborates previous results and further justifies the changes in structure and properties presented in previous sections. The results clearly prove that not crystalline structure, but interactions determine properties in the EVOH/additive system studied.

\subsection{Discussion}

The control of oxygen permeation has strong practical relevance. EVOH is one of the polymers with the smallest oxygen permeation, but many attempts are made to improve barrier properties even further $[38,47,50,55]$. Most of these approaches failed to result in sufficient improvement in this property. Instead of blending or using fillers, we added a small molecular weight additive to $\mathrm{EVOH}$ to decrease oxygen permeation with positive results. Although the change in the targeted property is relatively small, it is significant. Contrary to our original assumption the additive, i.e. Seed, does not act as a nucleating agent, but the effect observed can be assigned to molecular interactions.

Both molecular modeling and FTIR spectroscopy proved that the $-\mathrm{OH}$ groups of the polymer and the amide groups of the additive strongly interact with each other and this interaction results in all the observed changes in properties. Because of interactions, crystallinity decreases somewhat, but the decrease does not result in smaller stiffness and strength. At small concentrations the additive dissolves in the amorphous phase of the polymer decreasing molecular mobility. Decreased mobility results in increased stiffness and strength, but also increased overall deformability due to the physical cross-link points created by hydrogen bonds. Smaller mobility and hydrogen bonds decrease also oxygen diffusion, the direct effect of which is clearly shown by Figure 12. Smaller molecular mobility is accompanied by decreased free volume resulting in smaller OTR [69].

Up to the solubility level a very close linear correlation exists between oxygen permeability and the shift in the position of the carbonyl absorption of the amide groups. Above the solubility limit, which is around $2.0 \mathrm{wt} \%$ the additive forms a separate

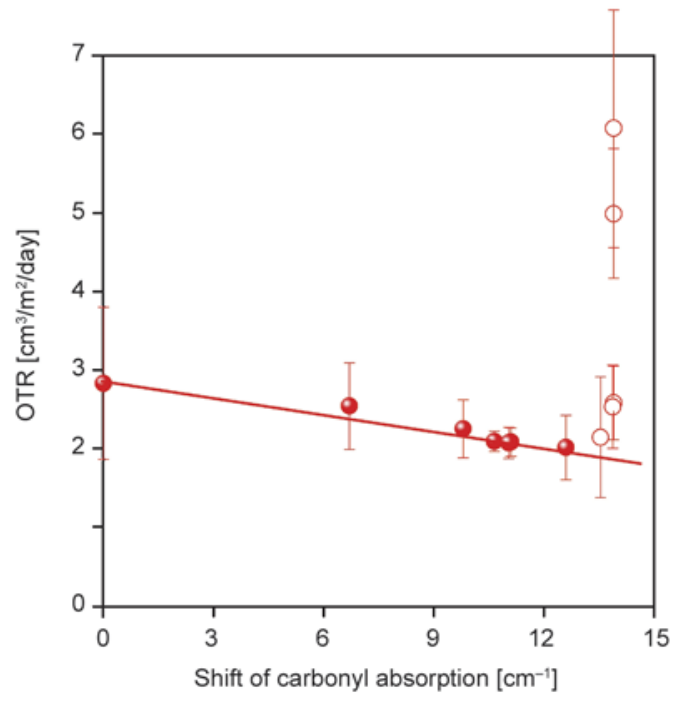

Figure 12. Direct correlation between oxygen permeation and molecular interactions (carbonyl shift); full symbols: below solubility level, empty symbols: separate additive phase

phase. Phase separation leads to a maximum in ultimate tensile properties (Figure 4), the appearance of new reflections in the XRD spectra (Figure 6) and the deviation from the straight line in Figure 12. The results strongly corroborate the effect of the additive on the structure and properties of $\mathrm{EVOH}$ and show a novel way to control oxygen permeation in such polymers.

\section{Conclusions}

Poly(ethylene-co-vinyl alcohol) of $48 \mathrm{~mol} \%$ ethylene content was modified with N,N'-bis(2,2,6,6tetramethyl-4-piperidyl)-isophthalamide to decrease the oxygen permeability of the polymer even further. The results showed that oxygen permeation decreased considerably when the additive was added at less than $2.0 \mathrm{wt} \%$ concentration. The decrease resulted from the interaction of the hydroxyl groups of the polymer and the amide groups of the additive. The dissolution of the additive in the amorphous phase of the polymer led to decreased crystallinity, but also in the decreased mobility of amorphous molecules. Stiffness and strength, but also deformability increased as a result. Above $2 \mathrm{wt} \%$, the additive forms a separate phase leading to the deterioration of properties. The success of the approach represents a novel way to control oxygen permeation in EVOH and in other polymers with similar functional groups capable of strong interactions. 


\section{Acknowledgements}

The authors are indebted to Erika Selmeci for the execution of the FTIR measurements, to István Sajó for the XRD experiments, and to Mihály Kállay for the DFT calculations. The research on heterogeneous polymer systems was financed by the National Scientific Research Fund of Hungary (OTKA Grant No. K 101124) and partly by the former Süd-Chemie AG, today Clariant, Business Unit Masterbatches, on functional packaging materials; we appreciate the support very much. One of the authors (KR) is grateful also to the János Bolyai Research Scholarship of the Hungarian Academy of Sciences.

\section{References}

[1] Summers L.: Intelligent packaging. Centre for Exploitation of Science and Technology. London (1992).

[2] Rooney M. L.: Active food packaging. Blackie Academic and Professional, London (1995).

[3] Brody A. L., Strupinsky E. R., Kline L. R.: Active packaging for food applications. CRC Press, London (2001).

[4] Ahvenainen R.: Novel food packaging techniques. Woodhead, Boca Raton (2003).

[5] Charles F., Sanchez J., Gontard N.: Absorption kinetics of oxygen and carbon dioxide scavengers as part of active modified atmosphere packaging. Journal of Food Engineering, 72, 1-7 (2006). DOI: 10.1016/j.jfoodeng.2004.11.006

[6] Byun Y., Darby D., Cooksey K., Dawson P., Whiteside S.: Development of oxygen scavenging system containing a natural free radical scavenger and a transition metal. Food Chemistry, 124, 615-619 (2011). DOI: 10.1016/j.foodchem.2010.06.084

[7] Busolo M. A., Lagaron J. M.: Oxygen scavenging polyolefin nanocomposite films containing an iron modified kaolinite of interest in active food packaging applications. Innovative Food Science and Emerging Technologies, 16, 211-217 (2012).

DOI: $10.1016 /$ j.ifset.2012.06.008

[8] Shirazi A., Cameron A. C.: Controlling relative humidity in modified atmosphere packages of tomato fruit. Hortscience, 27, 336-339 (1992).

[9] Mahajan P. V., Rodrigues F. A. S., Motel A., Leonhard A.: Development of a moisture absorber for packaging of fresh mushrooms (Agaricus bisporous). Postharvest Biology and Technology, 48, 408-414 (2008).

DOI: $10.1016 /$ j.postharvbio.2007.11.007

[10] Sandhya: Modified atmosphere packaging of fresh produce: Current status and future needs. LWT - Food Science and Technology, 43, 381-392 (2010). DOI: $10.1016 / j .1 w t .2009 .05 .018$

[11] Allinson J. G., Dansereau R. J., Sakr A.: The effects of packaging on the stability of a moisture sensitive compound. International Journal of Pharmaceutics, 221, 49-56 (2001). DOI: $10.1016 / \mathrm{S} 0378-5173(01) 00670-6$
[12] Waterman K. C., MacDonald B. C.: Package selection for moisture protection for solid, oral drug products. Journal of Pharmaceutical Sciences, 99, 4437-4452 (2010). DOI: $10.1002 / j p s .22161$

[13] García-García I., Taboada-Rodríguez A., López-Gomez A., Marín-Iniesta F.: Active packaging of cardboard to extend the shelf life of tomatoes. Food and Bioprocess Technology, 6, 754-761 (2013). DOI: $10.1007 / \mathrm{s} 11947-011-0759-4$

[14] Coma V.: Bioactive packaging technologies for extended shelf life of meat-based products. Meat Science, 78, 90-103 (2008).

DOI: $10.1016 /$ j.meatsci.2007.07.035

[15] Zema L., Sangalli M. E., Maroni A., Foppoli A., Bettero A., Gazzaniga A.: Activepackaging for topical cosmetic/drug products: A hot-melt extruded preservative delivery device. European Journal of Pharmaceutics and Biopharmaceutics, 75, 291-296 (2010).

DOI: 10.1016/j.ejpb.2010.03.007

[16] Boschetto D. L., Lerin L., Cansian R., Pergher S. B. C., Di Luccio M.: Preparation and antimicrobial activity of polyethylene composite films with silver exchanged zeolite-Y. Chemical Engineering Journal, 204-206, 210-216 (2012). DOI: $10.1016 /$ j.cej.2012.07.111

[17] Chen J., Brody A. L.: Use of active packaging structures to control the microbial quality of a ready-to-eat meat product. Food Control, 30, 306-310 (2013).

DOI: 10.1016/j.foodcont.2012.07.002

[18] Jacobsen C., Let M. B., Nielsen N. S., Meyer A. S.: Antioxidant strategies for preventing oxidative flavour deterioration of foods enriched with n-3 polyunsaturated lipids: A comparative evaluation. Trends in Food Science and Technology, 19, 76-93 (2008).

DOI: $10.1016 /$ j.tifs.2007.08.001

[19] Mexis S. F., Badeka A. V., Riganakos K. A., Karakostas K. X., Kontominas M. G.: Effect of packaging and storage conditions on quality of shelled walnuts. Food Control, 20, 743-751 (2009).

DOI: 10.1016/j.foodcont.2008.09.022

[20] Massey L. K.: Permeability properties of plastics and elastomers - A guide to packaging and barrier materials. William Andrew Publishing/Plastics Design Library, Norwich (2003).

[21] Armstrong R. B.: Effects of polymer structure on gas barrier of ethylene vinyl alcohol $(\mathrm{EVOH})$ and considerations for package development. in 'TAPPI PLACE Conference, Boston, USA' 1-6 (2002).

[22] Yamamoto T., Nishihara Y.: Barrier properties of EVOH at low temperatures and various humidity. Paper Film and Foil Converter (2001).

[23] Advani S. G., Shonaike G. O.: Advanced polymeric materials. CRC Press, Boca Raton (2003). 
[24] Lagaron J. M., Powell A. K., Bonner G.: Permeation of water, methanol, fuel and alcohol-containing fuels in high-barrier ethylene-vinyl alcohol copolymer. Polymer Testing, 20, 569-577 (2001). DOI: 10.1016/S0142-9418(00)00077-5

[25] Mokwena K. K., Tang J.: Ethylene vinyl alcohol: A review of barrier properties for packaging shelf stable foods. Critical Reviews in Food Science and Nutrition, 52, 640-650 (2011). DOI: $10.1080 / 10408398.2010 .504903$

[26] Cabedo L., Lagarón J. M., Cava D., Saura J. J., Giménez E.: The effect of ethylene content on the interaction between ethylene-vinyl alcohol copolymers and water - II: Influence of water sorption on the mechanical properties of EVOH copolymers. Polymer Testing, 25, 860-867 (2006). DOI: $10.1016 /$ j.polymertesting.2006.04.012

[27] Cava D., Cabedo L., Gimenez E., Gavara R., Lagaron J. M.: The effect of ethylene content on the interaction between ethylene-vinyl alcohol copolymers and water: (I) Application of FT-IR spectroscopy to determine transport properties and interactions in food packaging films. Polymer Testing, 25, 254-261 (2006). DOI: $10.1016 /$ j.polymertesting.2005.09.018

[28] Muramatsu M., Okura M., Kuboyama K., Ougizawa T., Yamamoto T., Nishihara Y., Saito Y., Ito K., Hirata K., Kobayashi Y.: Oxygen permeability and free volume hole size in ethylene-vinyl alcohol copolymer film: Temperature and humidity dependence. Radiation Physics and Chemistry, 68, 561-564 (2003).

DOI: $10.1016 / \mathrm{S} 0969-806 \mathrm{X}(03) 00231-7$

[29] Lagarón J. M., Giménez E., Gavara R., Saura J. J.: Study of the influence of water sorption in pure components and binary blends of high barrier ethylenevinyl alcohol copolymer and amorphous polyamide and nylon-containing ionomer. Polymer, 42, 95319540 (2001).

DOI: 10.1016/S0032-3861(01)00496-7

[30] Zhang Z., Britt I. J., Tung M. A.: Permeation of oxygen and water vapor through EVOH films as influenced by relative humidity. Journal of Applied Polymer Science, 82, 1866-1872 (2001).

DOI: 10.1002/app.2030

[31] Mokwena K. K., Tang J., Laborie M-P.: Water absorption and oxygen barrier characteristics of ethylene vinyl alcohol films. Journal of Food Engineering, 105, 436-443 (2011).

DOI: 10.1016/j.jfoodeng.2011.02.040

[32] López-Rubio A., Lagaron J. M., Giménez E., Cava D., Hernandez-Muñoz P., Yamamoto T., Gavara R.: Morphological alterations induced by temperature and humidity in ethylene--vinyl alcohol copolymers. Macromolecules, 36, 9467-9476 (2003).

DOI: $10.1021 / \mathrm{ma} 035346 \mathrm{j}$
[33] Aucejo S., Marco C., Gavara R.: Water effect on the morphology of EVOH copolymers. Journal of Applied Polymer Science, 74, 1201-1206 (1999).

DOI: 10.1002/(SICI)1097-4628(19991031)74:5<1201

$$
\because \text { AID-APP17>3.0.CO;2-8 }
$$

[34] Yamamoto T., Kanda T., Nishihara Y., Ooshima T., Saito Y.: Correlation study among oxygen permeability, molecular mobility, and amorphous structure change of poly(ethylene-vinylalcohol copolymers) by moisture. Journal of Polymer Science Part B: Polymer Physics, 47, 1181-1191 (2009).

DOI: $10.1002 /$ polb.21723

[35] Yeh J-T., Huang S-S., Yao W-H., Wang I-J., Chen CC.: Oxygen permeation resistance of polyethylene, polyethylene/ethylene vinyl alcohol copolymer, polyethylene/modified ethylene vinyl alcohol copolymer, and polyethylene/modified polyamide-ethylene vinyl alcohol copolymer bottles. Journal of Applied Polymer Science, 92, 2528-2537 (2004).

DOI: 10.1002/app.20215

[36] López-Rubio A., Lagarón J. M., Hernández-Muñoz P., Almenar E., Catalá R., Gavara R., Pascall M. A.: Effect of high pressure treatments on the properties of EVOHbased food packaging materials. Innovative Food Science and Emerging Technologies, 6, 51-58 (2005). DOI: 10.1016/j.ifset.2004.09.002

[37] Dhawan S., Barbosa-Cànovas G. V., Tang J., Sablani S. S.: Oxygen barrier and enthalpy of melting of multilayer EVOH films after pressure-assisted thermal processing and during storage. Journal of Applied Polymer Science, 122, 1538-1545 (2011).

DOI: $10.1002 / a p p .34267$

[38] Schut J. H.: Nine-layer. Plastics Technology, 51, 54-59 (2005).

[39] Schut J. H.: Microlayer films. Plastics Technology, 52, 54-60 (2006).

[40] Samios C. K., Kalfoglou N. K.: Acrylic-modified polyolefin ionomers as compatibilizers for poly(ethyleneco-vinyl alcohol)/aromatic copolyester blends. Polymer, 42, 3687-3696 (2001).

DOI: $10.1016 / \mathrm{S} 0032-3861(00) 00432-8$

[41] Lasagabáster A., Abad M. J., Barral L., Ares A., Bouza R.: Application of FTIR spectroscopy to determine transport properties and water-polymer interactions in polypropylene (PP)/poly(ethylene-co-vinyl alcohol) (EVOH) blend films: Effect of poly(ethylene-co-vinyl alcohol) content and water activity. Polymer, 50, 2981-2989 (2009).

DOI: 10.1016/j.polymer.2009.04.005

[42] Yeh J-T., Yao W-H., Du Q., Chen C-C.: Blending and barrier properties of blends of modified polyamide and ethylene vinyl alcohol copolymer. Journal of Polymer Science Part B: Polymer Physics, 43, 511-521 (2005). DOI: $10.1002 /$ polb.20344 
[43] Yeh J-T., Chen H-Y.: Blending and oxygen permeation properties of the blown films of blends of modified polyamide and ethylene vinyl alcohol copolymer with varying vinyl alcohol contents. Journal of Materials Science, 42, 5742-5751 (2007).

DOI: $10.1007 / \mathrm{s} 10853-006-0555-0$

[44] Papadopoulou C. P., Kalfoglou N. K.: Compatibility study of binary and ternary $\mathrm{PVOH} /$ polyolefin blends. Polymer, 38, 4207-4213 (1997). DOI: 10.1016/S0032-3861(96)01009-9

[45] Földes E., Pukánszky B.: Miscibility-structure-property correlation in blends of ethylene vinyl alcohol copolymer and polyamide 6/66. Journal of Colloid and Interface Science, 283, 79-86 (2005).

DOI: 10.1016/j.jcis.2004.08.175

[46] Lagarón J. M., Giménez E., Saura J. J., Gavara R.: Phase morphology, crystallinity and mechanical properties of binary blends of high barrier ethylene-vinyl alcohol copolymer and amorphous polyamide and a polyamide-containing ionomer. Polymer, 42, 73817394 (2001). DOI: $10.1016 / \mathrm{S} 0032-3861(01) 00204-\mathrm{X}$

[47] de Lima J. A., Felisberti M. I.: Poly(ethylene-co-vinyl alcohol) and poly(methyl methacrylate) blends: Phase behavior and morphology. European Polymer Journal, 44, 1140-1148 (2008).

DOI: $10.1016 /$ j.eurpolymj.2008.02.001

[48] Kim S. W., Hwang G. S.: A study on the morphology and properties of $\mathrm{PP} /($ Nylon-EVOH) blends. Applied Chemistry, 9, 45-48 (2005).

[49] Russo P., Acierno D., Maio L. D., Demma G.: Thermal and mechanical characterisation of films from Nylon 6/ EVOH blends. European Polymer Journal, 35, 12611268 (1999).

DOI: 10.1016/S0014-3057(98)00197-9

[50] Cabedo L. S., Giménez E., Lagaron J. M., Gavara R., Saura J. J.: Development of EVOH-kaolinite nanocomposites. Polymer, 45, 5233-5238 (2004). DOI: $10.1016 /$ j.polymer.2004.05.018

[51] Aktzi N., Nir Y., Wang D., Narkis M., Siegmann A.: EVOH/clay nanocomposites produced by melt processing. Polymer Composites, 22, 710-720 (2001). DOI: $10.1002 /$ pc. 10573

[52] Lucciarini J. M., Ratto J. A., Koene B. E., Powell B.: Nanocomposites study of ethylene co-vinyl alcohol and montmorillonite clay. in 'SPE ANTEC Proceeding, San Francisco, USA' 760-764 (2002).

[53] Artzi N., Narkis M., Siegmann A.: Review of meltprocessed nanocomposites based on EVOH/organoclay. Journal of Polymer Science Part B: Polymer Physics, 43, 1931-1943 (2005). DOI: $10.1002 /$ polb.20481

[54] Jeong H., Kim B., Kim E.: Structure and properties of EVOH/organoclay nanocomposites. Journal of Materials Science, 40, 3783-3787 (2005). DOI: $10.1007 / \mathrm{s} 10853-005-3719-4$
[55] Lagaron J. M., Cabedo L., Cava D., Feijoo J. L., Gavara R., Gimenez E.: Improving packaged food quality and safety. Part 2: Nanocomposites. Food Additives and Contaminants, 22, 994-998 (2005). DOI: $10.1080 / 02652030500239656$

[56] Kim S. W., Cha S-H.: Thermal, mechanical, and gas barrier properties of ethylene-vinyl alcohol copolymer-based nanocomposites for food packaging films: Effects of nanoclay loading. Journal of Applied Polymer Science, 131, in press (2013).

DOI: 10.1002/app.40289

[57] Lagaron J. M., Gimenez E., Sanchez-Garcia M. A., Ocio M. J., Fendler A.: Novel nanocomposites to enhance quality and safety of packaged foods. in 'Food Contact Polymers-Intenational Conference, Brussels, Belgium' p.6 (2007).

[58] Százdi L., Pozsgay A., Pukánszky B.: Factors and processes influencing the reinforcing effect of layered silicates in polymer nanocomposites. European Polymer Journal, 43, 345-359 (2007).

DOI: 10.1016/j.eurpolymj.2006.11.005

[59] Ábrányi Á., Százdi L., Pukánszky B. Jr., Vancsó G. J., Pukánszky B.: Formation and detection of clay network structure in poly(propylene)/layered silicate nanocomposites. Macromolecular Rapid Communications, 27, 132-135 (2006).

DOI: $10.1002 /$ marc.200500687

[60] Dominkovics Z., Hári J., Fekete E., Pukánszky B.: Thermo-oxidative stability of polypropylene/layered silicate nanocomposites. Polymer Degradation and Stability, 96, 581-587 (2011).

DOI: 10.1016/j.polymdegradstab.2010.12.012

[61] Franco-Urquiza E., Santana O. O., Gámez-Pérez J., Martínez A. B., Maspoch M. L.: Influence of processing on the ethylene-vinyl alcohol $(\mathrm{EVOH})$ properties: Application of the successive self-nucleation and annealing (SSA) technique. Express Polymer Letters, 4, 153-160 (2010). DOI: $10.3144 /$ expresspolymlett.2010.20

[62] Brückner S.: Estimation of the background in powder diffraction patterns through a robust smoothing procedure. Journal of Applied Crystallography, 33, 977-979 (2000).

DOI: $10.1107 / \mathrm{s} 0021889800003617$

[63] Zhao Y., Truhlar D. G.: Hybrid meta density functional theory methods for thermochemistry, thermochemical kinetics, and noncovalent interactions: The MPW1B95 and MPWB1K models and comparative assessments for hydrogen bonding and van der Waals interactions. The Journal of Physical Chemistry A, 108, 6908-6918 (2004).

DOI: $10.1021 / \mathrm{jp} 048147 \mathrm{q}$

[64] Krishnan R., Binkley J. S., Seeger R., Pople J. A.: Selfconsistent molecular orbital methods. XX. A basis set for correlated wave functions. The Journal of Chemical Physics, 72, 650-654 (1980). DOI: $10.1063 / 1.438955$ 
[65] Pukánszky B., Mudra I., Staniek P.: Relation of crystalline structure and mechanical properties of nucleated polypropylene. Journal of Vinyl and Additive Technology, 3, 53-57 (1997).

DOI: $10.1002 / \mathrm{vnl} .10165$

[66] Wunderlich B.: Thermal analysis of polymeric materials. Springer, Berlin (2005).

[67] Horváth Zs., Menyhárd A., Doshev P., Gahleitner M., Tranninger C., Kheirandish S., Varga J., Pukánszky B.: Effect of molecular architecture on the crystalline structure and stiffness of iPP homopolymers: Modeling based on annealing experiments. Journal of Applied Polymer Science, 130, 3365-3373 (2013).

DOI: 10.1002/app.39585
[68] Meeten G. H.: Optical properties of polymers. Elsevier, London (1986).

[69] Dhawan S., Varney C., Barbosa-Cánovas G. V., Tang J. M., Selim F., Sablani S. S.: Pressure-assisted thermal sterilization effects on gas barrier, morphological, and free volume properties of multilayer EVOH films. Journal of Food Engineering, 128, 40-45 (2014)

DOI: 10.1016/j.jfoodeng.2013.12.012 